\title{
An exploration of the reasons women give for choosing legal termination of pregnancy at Soshanguve Community Health Centre, Pretoria, South Africa
}

\author{
Carrien Steyn, Indiran Govender* iD and John Velaphi Ndimande \\ Department of Family Medicine and Primary Health Care, Sefako Makgatho Health Sciences University, Pretoria, South Africa \\ *Corresponding author, email: indiran.govender@gmail.com
}

Background: Termination of pregnancy (TOP) is one of the most commonly performed gynaecological procedures in the world and was legalised in South Africa in 1996 with the passing of the Choice on Termination of Pregnancy Act, 1996 (Act No. 29 of 1996). Utilisation of the TOP service increased significantly after the promulgation of the Act, to the extent that $7 \%$ of pregnant women in South Africa chose to terminate their pregnancies legally in 2012. Worldwide, women most commonly state their reasons for choosing TOP as a desire to stop or postpone childbearing. Although several international studies have been done in this regard, the reasons for women requesting legalised TOP in South Africa have not been explored in depth.

Methods: A qualitative study using the case-study approach and involving one-on-one open interviews with participants was done at the TOP Clinic at Soshanguve Clinic 3 with the aim of gaining more insight into this issue.

Results: The following themes emerged from the interviews: formal education not completed, financial difficulties, contraceptive failure, wrong timing, reasons relating to the existing family; and problems relating to the partner.

Conclusion: This study also gave insight into the complex personal and social contexts within which women make the decision to terminate their pregnancy, and the thoughtfulness with which they make their decisions.

Keywords: legal termination of pregnancy, reasons for choosing termination of pregnancy, financial difficulties, contraceptive failure

\section{Introduction}

Termination of pregnancy (TOP) is one of the most commonly performed gynaecological procedures in the world. Globally, about 41.6 million induced TOPs were performed in 2003, and that number increased to 46 million in 2013.,

South Africa legalised TOP in 1996, with the Choice on Termination of Pregnancy Act. ${ }^{3}$ This act allowed for safe, effective, affordable and acceptable methods of TOP. ${ }^{4}$ Utilisation of the TOP services increased significantly after this, to the extent that $7 \%$ of pregnant women in South Africa legally terminated their pregnancies in 2012. ${ }^{3}$

The demographic characteristics of women who chose TOP have been studied locally and internationally. In South Africa the majority of women terminating their pregnancies were between the ages of 20 and 30 years. ${ }^{3,5}$ In sub-Saharan Africa the majority of women who opted for TOP were unmarried. ${ }^{2,6-8}$ In Hammanskraal, South Africa, $36.1 \%$ of the women who chose TOP were single, $59.4 \%$ were widowed and $73 \%$ had at least one child. ${ }^{3}$

Other characteristics of interest in these women were level of education and employment status. In Hammanskraal, South Africa, $28 \%$ of these women were high-school learners, $46.4 \%$ had completed high school and $35.5 \%$ had no formal education. ${ }^{3}$ Unemployment or currently being at school seemed to be a common problem amongst these women. In the Hammanskraal study, $73.5 \%$ of women requesting TOP were unemployed. ${ }^{3}$

Several international studies have explored the reasons women gave for terminating their pregnancies. These were categorised into reasons focused on the women; for example, wrong timing to be pregnant, not being married, and being too young;, ${ }^{9} 10$ reasons related to other factors that included contraceptive failure, intimate partners, extended families and finances; ${ }^{10-12}$ and complex and contingent reasons, including becoming pregnant as the result of rape, sexual assault or incest. ${ }^{1,3,10,13}$ Worldwide, women most commonly stated their reason for choosing TOP as a desire to stop or postpone childbearing, ${ }^{3}$ but published quantitative studies still do not adequately explain the reasons why women in South Africa opt to terminate their pregnancies.

\section{Methodology}

\section{Study design}

We conducted a qualitative study using the case-study approach with one-on-one open interviews.

\section{Study setting}

Soshanguve Clinic 3 is situated approximately $30 \mathrm{~km}$ north-west of Pretoria, in Gauteng Province. It is a community health centre in a semi-urban area. Most of the settlements in the region are formal settlements and some are semi-formal settlements. Sixteen TOP procedures by manual vacuum aspiration are carried out every week.

\section{Study population}

The study population were women attending the TOP Clinic from January 1, 2017 to February 28, 2017. Purposive sampling of information-rich participants was conducted..$^{14}$ Ten participants were interviewed, as data saturation was reached when interviewing participants nine and ten.

\section{Materials}

The interview guide contained a section for basic demographic information, and a section for the interview. The interview section contained a number of probes to ensure that the information obtained was complete. The role of emotional factors, finances, family and partners in the women's decisions to opt for TOP were probed. 


\section{Data collection}

The researchers explained the aims and objectives of the study to every possible participant. Informed written consent was obtained from all participants.

The opening exploratory question was:'Why did you come for an abortion today?' Each interview lasted between 45 and 60 minutes. All of the interviews were conducted in English. All participants were fluent in English and thus language was not a barrier to the data-collection process.

The interviews were audio recorded, and additional notes were made in the interview notes and in a research diary during the course of the interview, to ensure data triangulation. The voice recordings and interview notes were allocated corresponding numbers to ensure congruence of the information. After each interview the interview notes were placed in an envelope (using a separate envelope for each participant). The interviews were transcribed verbatim.

Confidentiality and anonymity were maintained throughout the research process. Pseudonyms were used, and the pseudonyms were noted on the interview guide that was also placed in the envelope, instead of the participant's name. Only the researcher knows the actual participants.

\section{Data analysis}

The data were analysed by transcribing the data, cross-checking all the themes and verifying all the information. During data analysis, the researcher familiarised herself with the data by reading transcripts and observation notes and listening to voice recordings, while a thematic index was developed by organising information into categories and assigning codes to each of the categories. Indexing was done by dividing the data into categories. Charting was done by bringing all the data with the same code together in one place from all the data sources with the 'cut-and-paste' method, and thereafter the data were interpreted..$^{15}$

\section{Trustworthiness}

Credibility was assured by using recognised research methods, and by the researcher's prolonged engagement with the reasons why these women terminated their pregnancies. To further enhance credibility, participants were given enough time to express themselves. The researcher practised engagement allowing the participants to become accustomed to the researcher and to build rapport, which may have encouraged the participants to volunteer more sensitive information than they had at the beginning of the interviews. The interviews were audio-recorded, and all recordings were numbered and saved. Typing and storing of information enhanced credibility and stability. Direct quotations were used to provide rich data to support the themes. A thick description, including a detailed description of the study setting, the selection of participants and the findings, was done to allow transferability. The methods were described in detail to ensure that the study could be replicated elsewhere with ease.

To ensure that the findings reflect the experiences and ideas of the participants themselves, the researchers complied with the rules of neutrality and remained non-judgemental. Before the interviews were started, the interviewing researcher (CS) was interviewed by another researcher (IG) to make the researcher aware of 'self' as a research instrument; in other words, reflexivity was addressed. ${ }^{15}$
To enable triangulation, audio recordings, research diary entries and research notes were completed for each participant.

\section{Ethical considerations}

Ethical clearance for this study was obtained from the Sefako Makgatho University Research Ethics Committee (SMUREC/M/197/2016: PG). Permission for the study was also obtained from the management of Soshanguve Clinic 3.

\section{Results}

The demographic data of the participants are presented in Table 1. The mean age of the participants was 24.3 years, with the maximum age being 32 years and the minimum age being 19 years old. The mean parity of the group was one.

The gestational age of all participants was less than 12 weeks, as required by law for a primary care facility; however, the exact gestational age was not recorded by the researchers.

\section{Themes}

The reasons for TOP recurred as the interviews proceeded and data saturation occurred with participants nine and ten. None of the participants provided only one reason for terminating their pregnancies. Five of the participants had two reasons, two participants had three reasons, and three of the participants had four reasons that motivated their action.

Table 1: Demographic data of participants

\begin{tabular}{|c|c|}
\hline Characteristic & No. of participants \\
\hline \multicolumn{2}{|l|}{ Age (years): } \\
\hline 19 & 3 \\
\hline 21 & 1 \\
\hline 23 & 1 \\
\hline 25 & 1 \\
\hline 26 & 1 \\
\hline 29 & 1 \\
\hline 30 & 1 \\
\hline 32 & 1 \\
\hline \multicolumn{2}{|l|}{ Number of existing children: } \\
\hline 0 & 4 \\
\hline 1 & 4 \\
\hline 2 & 2 \\
\hline \multicolumn{2}{|l|}{ Highest level of schooling: } \\
\hline Primary school & 1 \\
\hline High school & 9 \\
\hline \multicolumn{2}{|l|}{ Employment status: } \\
\hline Employed & 1 \\
\hline Unemployed, not studying & 4 \\
\hline Unemployed, studying & 5 \\
\hline \multicolumn{2}{|l|}{ Marital status: } \\
\hline Never married & 9 \\
\hline Married & 1 \\
\hline \multicolumn{2}{|l|}{ Living arrangements: } \\
\hline Alone & 1 \\
\hline With relatives & 6 \\
\hline With husband or partner & 3 \\
\hline \multicolumn{2}{|l|}{ Number of previous TOPs: } \\
\hline 0 & 10 \\
\hline
\end{tabular}




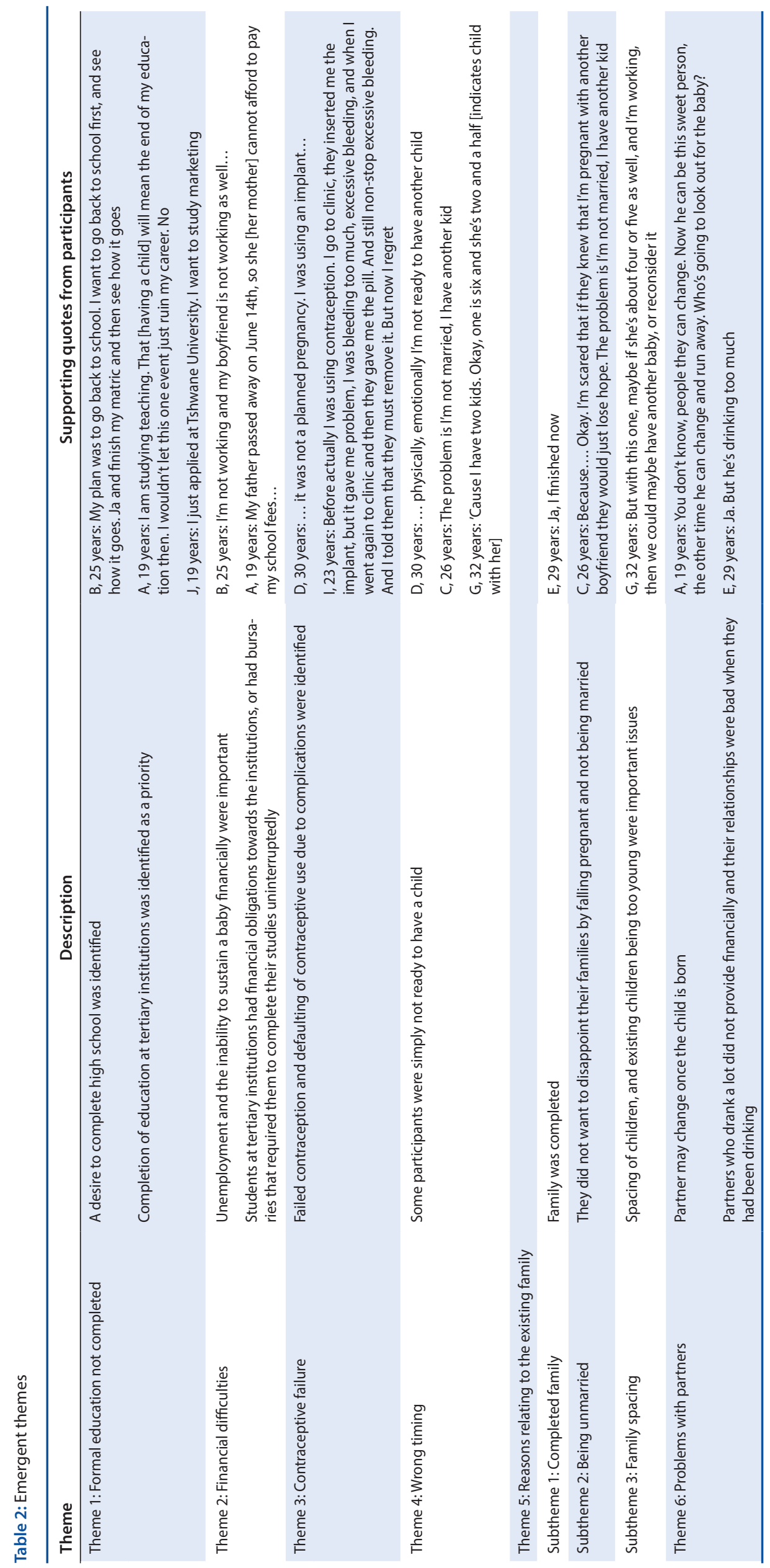


The women's difficulty in making this decision and their emotional burdens are illustrated by the following response:

I, 23 years: Eish, now, yoh, my heart is very painful, because to terminate it's a dilemma. It's a difficult decision, tough decision.

Six main themes emerged and are summarised in Table 2.

\section{Discussion}

Women seldom have a single reason why they choose TOP, and the decision involves far more thought, consideration and contemplation than the woman merely deciding not to continue with the pregnancy. $3,5,10,11,13$ Unintended pregnancy can be a cause of emotional stress, ${ }^{5}$ and feelings of relief, guilt, grief, anguish, release, emptiness, shame, doubt and anxiety before and after the TOP are common. ${ }^{16-18}$

The reasons for women choosing to terminate their pregnancies in our study were formal education not completed, financial difficulties, contraceptive failure, wrong timing, reasons relating to the existing family, and problems relating to the partner. All the participants had more than one of these reasons to terminate their pregnancy. From a society level, policy-makers need to be aware of these challenges and empower women to plan their pregnancies more effectively.

The themes that were derived from this research could guide health-care providers in family planning clinics or practices to counsel patients more effectively, and to have a better understanding of their patients who request TOP. They can also provide a background for future community-orientated primary care projects aimed at preventing unwanted pregnancies and TOPs.

We will now explore the themes further.

\section{Theme 1: Formal education not completed}

Many international studies report that the education level of women played a role in their decision to have TOPs. ${ }^{6,9,10}$ According to previous research, most TOPs were obtained by women who had at least a secondary education. ${ }^{6}$ Literature showed that the desire not to disrupt education was sub-grouped under 'wrong timing, and was not stated as a reason on its own. ${ }^{10}$

In Cameroon it was seen that women who were attending school were, regardless of their age, far more likely to request TOP than women who were not attending school. TOP would be defended and even recommended for school-aged pregnant girls, due to the importance that Cameroonians place on education. ${ }^{8}$

In Nigeria, 53.4\% of the women who sought TOP had some secondary education, or had already graduated from secondary school. The most common reason for requesting TOP that $30 \%$ of the Nigerian women gave was the fact that they did not want pregnancy to interrupt their education. ${ }^{7}$

Three South African studies found varying results on the educational levels of women who requested TOP. These studies showed that the majority of the women were attending high school, and only one study had participants who had completed tertiary education.,16,19 However, none of the previously conducted South African studies mentioned a desire to complete education as a reason to request TOP.
The desire to complete formal education as a reason to request TOP correlated mostly with results that were found in Cameroon and Nigeria. Reviews showed that completing education was mentioned, but not given as a primary reason for TOP internationally. This is regardless of the participants' level of education. ${ }^{9-11}$ This study therefore reveals new information about the women of Soshanguve.

\section{Theme 2: Financial difficulties}

International reviews support financial difficulties as a reason to request TOP.9-11 This was the second most important reason to request TOP in a review done previously, and was also given as a reason in both developed and developing countries. ${ }^{9}$

Financial difficulties are an important reason for women to request TOP in South Africa. ${ }^{3}$ In Cape Town, socio-economic hardship was mentioned as the most important reason for women to request TOP, with 22 of the 24 respondents being unemployed. ${ }^{20}$ In a district hospital in KwaZulu-Natal the majority of women requesting TOP did so because of financial considerations. ${ }^{5}$ In Pretoria, $75.4 \%$ of the participants in a study requested TOP due to financial problems, ${ }^{16}$ and in the Free State $32.1 \%$ of women said that financial difficulties were their motivation to request TOP. ${ }^{19}$

\section{Theme 3: Contraceptive failure}

The lowest abortion rates in the world are found in Northern and Western Europe where contraception is readily and easily

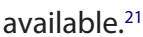

In Tunisia, $65 \%$ of women who underwent a first abortion and $79 \%$ of women who requested a repeat abortion did not use any contraception. High contraceptive failure rates were reported in this study, as well as a lack of knowledge about birth control methods and their availability.

The only method of contraception that is taught in school in southern Cameroon is periodic abstinence, which results in a high number of unintended pregnancies. Many of these women request TOP. ${ }^{8}$ Similarly, $85 \%$ of women who requested abortion in Nigeria did not use any contraception. A large number of women experienced failed contraception when using injectables and intra-uterine devices. The reasons for these failures have not been investigated. ${ }^{7}$

In KwaZulu-Natal, South Africa, $89.4 \%$ of study respondents who underwent TOP did not use any contraception. ${ }^{5}$ In the Free State, $73 \%$ of respondents did not use any contraception, and the methods that were most commonly used were the male condom, oral contraceptives and injectables. ${ }^{19}$

In a Cape Town study, inconsistent contraceptive use, no contraception and contraceptive failure contributed to a large number of unwanted pregnancies. Problems associated with male condom use was described as a major source of contraceptive failure..$^{20}$

Another South African study showed that $66 \%$ of women terminating their pregnancies reported contraceptive failure. The causes for the contraceptive failure were reported to be condom failure, incorrect use of oral contraceptives or injectables, using the calendar method of family planning, using methods prescribed by traditional healers, using antibiotics with oral contraceptives, failed tubal ligation, and failed intra-uterine contraceptive devices. ${ }^{16}$ 
Poor knowledge of contraception, poor contraceptive practices and contraceptive failure are therefore not limited to Soshanguve.

\section{Theme 4: Wrong timing}

One review grouped women who were not ready for motherhood with the desire not to disrupt work, education and life plans under 'wrong timing' as a reason to request TOP. ${ }^{10}$ In most of the studies not being ready for a first child or another child was given as one of the four most important reasons for women to request TOP.

In the Hammanskraal study, $73 \%$ of respondents requested TOP because they were not ready to be parents. ${ }^{3}$

\section{Theme 5: Reasons relating to the existing family}

\section{Subtheme 1: Family is complete}

Stating that the family was complete, or that the woman already had enough children, was a reason for TOP in many international studies. This reason was often supported by other reasons, such as financial obligations, not wanting to start over, and already having children of both genders. ${ }^{10}$

Controlling family size was given as a reason for TOP by about $50 \%$ of respondents in a review done of 27 developed and developing countries. It was suggested that factors such as poverty, unemployment and the inability to afford education for another child also play an important role in women's decision to restrict their family size. ${ }^{9}$

In Pretoria, South Africa, 6\% of abortion seekers said that they already had too many children. ${ }^{16}$

\section{Subtheme 2: The woman is not married}

Being unmarried as a reason to request TOP was an important factor internationally, and was influenced by factors such as religion, tradition, ethnicity and culture. Only a few of the women who requested TOP in sub-Saharan countries were married. ${ }^{6}$ In our study, only one of the participants was married.

In a survey done in Cameroon, nearly all the terminations of pregnancy were requested by unmarried women, whilst married women requested abortions only when there was a compelling medical reason to do $50 .{ }^{8}$ In Nigeria, $63 \%$ of the women who requested TOP had never been married. The second most common reason for TOP was being unmarried, because they did not want to bear illegitimate children. ${ }^{7}$

South African studies showed similar results. In a study done in Pretoria, $85 \%$ of the respondents who requested TOP were unmarried, ${ }^{16}$ and in a district hospital in KwaZulu-Natal, 93\% of the women who requested TOP were single. ${ }^{5}$ In Hammanskraal, $4 \%$ of the women who requested TOP were married. However, in none of these studies was being unmarried given as a reason for TOP. 3,5

\section{Subtheme 3: Family spacing}

In a review of 27 countries, $50 \%$ of the women in both developed and developing countries stated that family spacing was their reason for TOP. Some said that their last child was still too young for them to have another child, and other women had other reasons to delay having another child. ${ }^{9}$ Similar results were found in South Africa.

\section{Theme 6: Problems relating to the partner}

Studies report that partner-related reasons account for one-third of all reasons why women seek to terminate their pregnancies. ${ }^{12}$ Domestic violence is more common among women who request TOP than in the general population. ${ }^{22}$ Physical, sexual and emotional abuse was a common finding globally in women requesting TOP. ${ }^{23}$ Between $24 \%$ and $40 \%$ of women who requested TOP had a history of abuse. ${ }^{24}$

In Tunisia there is a high rate of TOP among women who experienced conflicts, physical or sexual abuse. In a group of women who requested a repeat TOP, the rate of abuse was $90 \%$.

In sub-Saharan Africa, intimate partner violence (IPV) ranges from $25 \%$ to $48 \%$ in countries such as Uganda, Zambia, Kenya and South Africa. In Cameroon the rate is higher, and as many as $50 \%$ of women who terminate their pregnancies reported at least one form of abuse. There is strong evidence of an association between IPV and TOP. ${ }^{25}$

The South African society is violent. Both the oppression of women and IPV are characteristic of most South African social contexts, where the former is widely seen as culturally acceptable. ${ }^{26}$ In a study done in the Free State, $2 \%$ of the women who requested TOP did so after having been raped..$^{19}$ The Hammanskraal study reported that $10 \%$ of respondents had a history of physical abuse, $1 \%$ had a history of sexual abuse or coercion, $74 \%$ had a history of substantial conflict and fighting with their partners, and only $12 \%$ reported a good relationship with their partners. ${ }^{3}$

Problems relating to the partner are given by women globally as a reason to request TOP. In the light of our South African context, it is surprising that only two women reported problems relating to their partners.

\section{Conclusion}

Women who terminate their pregnancies at Soshanguve Clinic 3 seem to do so after considering the multiple challenges in their lives. These unplanned and unwanted pregnancies adversely influence all facets of their lives, such as their studies, family relationships and financial situation. All the women had more than one factor that contributed to them opting to terminate their pregnancies, and this choice was not an easy decision. The decision to terminate their pregnancies usually involved much consideration and contemplation.

Funding - This research was partially funded by the Discovery Foundation.

Disclosure statement - No potential conflict of interest was reported by the authors.

\section{ORCID}

Indiran Govender (iD) http://orcid.org/0000-0001-6062-8981

\section{References}

1. El Mhamdi SE, Ben Salah A, Bouanene I, Hlaiem I, Hadhri S, Maatouk $W$, et al. Obstetric and psychological characteristics of women seeking multiple abortions in the region of Monastir (Tunisia): results of a cross sectional design. BMC Women's Health. 2015;15: 84. https://doi.org/10.1186/s12905-015-0198-x

2. Holla R, Kanchan T, Unnikrishnan B, Kotian MS, Kumar N, et al. Profile of women seeking medical termination of pregnancy in South India. BJOG 2014;125:253-5. 
3. Ndwambi A, Govender I. Characteristics of women requesting legal termination of pregnancy in a district hospital in Hammanskraal. South Africa. SAJID. 2015;30(4):129-33.

4. Mendes JF, Basu D, Basu JK. Addressing the demand for termination of pregnancy services in district health facilities in Johannesburg. SAMJ. 2010;100(10):614.

5. Ngene NC, Ross A, Moodley J. Characteristics of women having first trimester termination of pregnancy at a district hospital in KwaZuluNatal. SAJEl. 2013;28(2):102-5.

6. Bankole A, Singh S, Haas T. Characteristics of women who obtain induced abortion: a worldwide review. International Family Planning Perspectives. 1999;25(2):68-77. https://doi.org/10.2307/2991944

7. Oye-Adeniran BA, Adewole IF, Umoh AV, Fapohunda OR, Iwere N. Characteristics of Abortion Care Seekers in South-Western Nigeria. Afr J Rep Health. 2004;8(3):81-91. https://doi.org/10.2307/3583395

8. Johnson-Hanks J. The lesser shame: abortion among educated women in southern Cameroon. Soc Sci Med. 2002;55:1337-1349. https://doi.org/10.1016/S0277-9536(01)00276-3

9. BankoleA,SinghS, HaasT.Reasonswhywomenhaveinducedabortions: evidence from 27 countries. IntFam Plan Perspect. 1998;24(3):117-128. https://doi.org/10.2307/3038208

10. Kirkman M, Rowe $H$, Hardiman $A$, et al. Reasons women give for abortion: a review of the literature. Archives of Women's Mental Health. 2009;12:365-378. https://doi.org/10.1007/s00737-009-0084-3

11. Kirkman M, Rosenthal D, Mallett $S$, et al. Reasons women give for contemplating or undergoing abortion: a qualitative investigation in Victoria. Sexual \& Reproductive Healthcare. 2010;1:149-55. https://doi.org/10.1016/j.srhc.2010.08.001

12. Chibber KS, Biggs MA, Roberts SCM, et al. The role of intimate partners in women's reasons for seeking abortion. Sex Reprod Healthc. 2014;24(1):e131-8.

13. Finer LB, Frohwirth LF, Dauphinee SS, et al. Reasons US women have abortions: qualitative and quantitative perspectives. Int Perspect Sex Reprod Health. 2005;37(3):110-8. https://doi.org/10.1363/3711005

14. Reid S, Mash B. African primary care research: qualitative interviewing in primary care. PHCFM. 2014;6(1):1.632.
15. Mabuza LH, Govender I, Ogunbanjo GA, et al. African primary care research: qualitative data analysis and writing results. PHCFM. 2014;6(1):640.

16. Kirkby RE, Blitz JJ, Kluyts T. The profile of the first women presenting for elective termination of pregnancy at the Pretoria Academic Hospital. SA Fam Prac J. 2001;23(3):11-16.

17. Kero A, Högberg $U$, Jacobsson L, Lalos A. Legal abortion: a painful necessity. Soc Sci Med. 2001;53:1481-90. https://doi.org/10.1016/S0277-9536(00)00436-6

18. Subramaney U, Wyatt GE, Williams JK. Of ambivalence, shame and guilt: perceptions regarding termination of pregnancy among South African women. S Afr Med J. 2015;105(4):283-4. https://doi.org/10.7196/SAMJ.9419

19. Lang F, Joubert G, Prinsloo EAM. Is pregnancy termination being used as a family planning method in the Free State? SA Fam Pract J. 2005;47(5):52-55.

20. Orner P, De Bruyn M, Harries J, et al. A qualitative exploration of HIVpositive women's decision-making regarding abortion in Cape Town. S Af SAHARA J. 2010;7(2): 44-51.

21. Cohen SA. Facts and consequences: legality, incidence and safety of abortion worldwide. Guttmacher Inst. 2009;12(4):2-6.

22. Woo J, Fine P, Goetzl L. Abortion disclosure and the association with domestic violence. ACOG. 2005;105(6): 1329-34.

23. Hall M, Chappell LC, Parnell BL, et al. Associations between intimate partner violence and termination of pregnancy: a systematic review and meta-analysis. PLOS MED. 2014;11(1):1-25.

24. Williams GB, Brackley MH. Intimate partner violence, pregnancy and the decision for abortion. Issues Mental Health Nurs. 2009;30:272-8. https://doi.org/10.1080/01612840802710902

25. Alio AP, Salihu HM, Nana PN, et al. Association between intimate partner violence and induced abortion in Cameroon. BJOG. 2010;112:83-87.

26. Joyner K, Mash B. A comprehensive model for intimate partner violence in South African primary care: action research. BMC Health Ser Res. 2012;12:653. https://doi.org/10.1186/1472-6963-12-399

Received: 24-10-2017 Accepted: 14-01-2018 